\title{
Bacterial translocation and immunohistochemical measurement of gut immune function
}

\author{
N P Woodcock, J Robertson, D R Morgan, K L Gregg, C J Mitchell, J MacFie
}

\begin{abstract}
Aims-The local immune response in the small bowel mucosa might play a role in bacterial translocation (BT). The aim of this study was to quantify immune cells and secretory antibodies in the small bowel mucosa, and relate this to BT as assessed by culture of a mesenteric lymph node.
\end{abstract}

Methods-Immunohistochemical techniques were used to measure the frequency of plasma cells and IgA and IgM positive cells in the lamina propria and semiquantitatively to assess mucosal surface IgA and IgM values in small bowel specimens obtained from 11 patients in whom positive evidence of BT had been identified in a mesenteric lymph node harvested at the time of laparotomy. These were compared with similar specimens obtained from 11 patients in whom a similar lymph node had yielded no growth.

Results-BT was associated with a significantly increased median frequency of plasma cells $(p<0.01)$ and IgA positive cells $(p<0.05)$ in the lamina propria. The frequency of IgM positive cells was also higher in these patients, although this difference was not significant. In addition, semiquantitatively scored IgA and IgM concentrations at the mucosal surface were both significantly higher in the patients in whom BT had been identified ( $p=0.006$ and 0.016 , respectively). Conclusion-Higher numbers of plasma cells and higher IgA and IgM values are present in the small bowel mucosa of patients in whom BT has been shown to occur, suggesting an increased local immune response.

(f Clin Pathol 2001;54:619-623)

Gastroenterology Unit and Department of Histopathology,

Scarborough Hospital, Woodlands Drive, Scarborough

YO12 6QL, North

Yorkshire, UK

N P Woodcock

J Robertson

D R Morgan

K L Gregg

C J Mitchell

$\mathrm{J}$ MacFie

Correspondence to: $\mathrm{Mr} \mathrm{J}$ MacFie

Johnmacfie@aol.com.uk

Accepted for publication 16 February 2001 barrier function, and deficiencies in host immunity. ${ }^{5}$ Our own and other studies have established an association between bacterial colonisation of the proximal gastrointestinal tract, BT, and septic morbidity, ${ }^{67}$ but have failed to confirm a causal relation between alterations in parameters of intestinal barrier function and $\mathrm{BT}^{8}$

A recent study of patients with intraabdominal sepsis demonstrated a significant reduction in $\operatorname{IgA}$ and $\operatorname{IgM}$ positive plasma cells in the lamina propria of the small bowel mucosa, and reduced immunoglobulin values at the mucosal surface. ${ }^{9}$ This paper proposed that the stress response induced by severe sepsis results in a decrease in immunoglobulin production by mucosal plasma cells, facilitating the adherence of luminal bacteria to the enterocyte surface, which is an important initial step in the process of translocation. ${ }^{10}$ However, BT was itself not assessed in this study.

The aim of our study was to investigate whether BT is associated with changes in gut immune function. Standard morphology and immunohistochemical techniques were used to measure the frequency of immune cells in the lamina propria, and immunohistochemistry alone to assess mucosal surface immunoglobulins in specimens of small bowel obtained at laparotomy. The occurrence of BT was determined by culture of a mesenteric lymph node.

\section{Patients and methods}

All patients included in our study were under the care of the combined gastroenterology unit at Scarborough Hospital. Approval for the study was obtained from the locally organised research ethics committee.

The patients were identified from a database containing the details of subjects included in a larger prospective study of $\mathrm{BT}$, the results of which have been published previously. ${ }^{2} \mathrm{~Pa}-$ tients were selected if they had undergone a small bowel resection as part of the therapeutic surgical procedure, and stored tissue was available for analysis of gut immune function. These data have not been reported previously. The first group of patients (BT positive group) comprised subjects in whom BT had been confirmed by positive bacterial culture from a mesenteric lymph node (MLN). Previous animal studies have suggested that culture of lymph nodes from the ileocolic mesentery constitutes the gold standard method of assessment of BT. ${ }^{11}$ The same number of patients with a negative MLN were selected at random as controls (BT negative group). 
Table 1 Demographic data

\begin{tabular}{lll}
\hline & $\begin{array}{l}\text { BT positive group } \\
(n=11)\end{array}$ & $\begin{array}{l}\text { BT negative group } \\
(n=11)\end{array}$ \\
\hline $\begin{array}{l}\text { Male to female ratio } \\
\text { Median age (interquartile range) }\end{array}$ & $3: 8$ & $5: 6$ \\
Diagnosis & 70 years $(54-74)$ & 71 years $(60-81)$ \\
$\quad$ Colorectal carcinoma & 3 & 8 \\
Ulcerative colitis & 2 & 3 \\
Strangulated femoral hernia & 2 & 0 \\
Crohn's disease & 1 & 0 \\
Angiodysplasia & 1 & 0 \\
Benign small bowel stricture & 1 & 0 \\
Enteroenteric fistula & 1 & 0 \\
\hline BT, bacterial translocation & &
\end{tabular}

TISSUE PROCESSING

The segments of normal small intestine removed at laparotomy had been fixed in $10 \%$ formal saline for between one and five days from the time of operation, and then processed to a paraffin wax block for storage. Sections were dewaxed in xylene and endogenous peroxidases were blocked using $1 \%$ hydrogen peroxide in methanol. Optimal unmasking of antibodies was achieved by incubating sections in protease $(10 \mathrm{mg}$ in $100 \mathrm{ml}$ Tris buffered saline (TBS)) at $40^{\circ} \mathrm{C}$ for five minutes, followed by a five minute wash in running water and a further five minute wash in TBS.

Each section was treated with normal horse serum for 30 minutes to reduce background staining. Rabbit antibodies against IgM and IgA were used at dilutions of $1 / 1000$ and $1 / 1500$, respectively, and sections were incubated for 60 minutes. After TBS washes, biotin labelled secondary antibodies at a dilution of 1/200 were applied for 30 minutes. Slides were then washed in TBS, after which avidin-biotin complex diluted according to the manufacturer's instructions was applied for 30 minutes, followed by further TBS washes.

Demonstration of horseradish peroxidase was achieved using the substrate 3'3diaminobenzene tetrahydrochloride. Sections were then counterstained with haematoxylin, dehydrated, cleared, and mounted in DPX mountant. Known positive control sections were included in the batch of immunostained specimens, and negative controls were provided by incubating sections from the same block with TBS in place of primary antibody.

To eliminate concerns that the intensity of staining could be influenced by laboratory temperature or duration of fixation of the small bowel specimens, ${ }^{12}$ an initial experiment was performed whereby multiple segments from the same length of bowel were fixed at $16^{\circ} \mathrm{C}$, $22^{\circ} \mathrm{C}$, or $27^{\circ} \mathrm{C}$ for one, three, or five days before processing to wax and subsequent staining as described above. These criteria were chosen as representative of the range of normal practice in our laboratory. No significant differences in staining intensity for IgA or IgM were observed between the various segments. To avoid the variability of immunohistochemical staining that can occur when multiple staining runs are performed for a particular antigen or epitope, the staining for $\operatorname{IgA}$ and $\operatorname{IgM}$ were each performed as a single run. This obviously limited the number of patients that could be studied.
QUANTITATION

After staining each specimen was analysed by one consultant histopathologist (DRM), who was blinded as to whether the patient had translocated or not. Five parameters were assessed: (1) plasma cell numbers, (2) frequency of IgA positive cells in the lamina propria, (3) frequency of IgM positive cells in the lamina propria, (4) IgA values at the mucosal surface, and (5) IgM values at the mucosal surface. The plasma cells were identified by cell morphology alone, whereas IgA positive and IgM positive cells were identified according to whether or not they stained positively for the respective immunoglobulins. Cell numbers in the lamina propria were calculated using a $100 \mathrm{~mm}^{2}$ graticule. To overcome the problem of glands encroaching upon the field of view the median total cell count in a random $10 \mathrm{~mm}^{2}$ in five separate squares was multiplied by a factor of 10 to give a value in number of cells $/ \mathrm{cm}^{2}$. A semiquantitative method was used for the assessment of $\operatorname{IgA}$ and $\operatorname{IgM}$ values at the mucosal surface, whereby each specimen was scored 0-3 according to a subjective assessment of intensity of staining for the respective immunoglobulin ( 0 , no staining; 1 , low; 2, moderate; 3 , high intensity). Until the technology for computer assisted image analysis is validated and becomes widely available this is the acknowledged method of analysis. ${ }^{13} 14$

All non-parametric data are expressed as medians (range). Statistical analysis of the quantitative data was performed using the Mann-Whitney $U$ test. The qualitative data were analysed using Fisher's exact test for small numbers, using the mid $\mathrm{p}$ value because it is less conservative and therefore more powerful. ${ }^{15} \mathrm{~A} p$ value of $\leqslant 0.05$ was classed as significant.

\section{Results}

In total, 22 patients were studied, 11 of whom were BT positive and $11 \mathrm{BT}$ negative. Table 1 shows the demographic data, including indications for surgery. Fourteen organisms were grown on culture of the MLNs, of which nine were enteric species: Escherichia coli $(\mathrm{n}=8)$, Citrobacter freundii $(\mathrm{n}=1)$, Staphylococcus epidermidis $(\mathrm{n}=2)$, Streptococcus $\mathrm{spp} .(\mathrm{n}=2)$, and Pseudomonas aeruginosa $(\mathrm{n}=1)$.

The median frequency of plasma cells in the BT positive patients was $20 / \mathrm{cm}^{2}$ (range $<10-$ 70 ), significantly higher than that in the BT negative patients (median concentration, $<10$ / $\mathrm{cm}^{2}$; range, $<10-40 ; \mathrm{p}<0.01$, Mann-Whitney $\mathrm{U}$ test). The median frequency of IgA positive cells in the BT positive patients $\left(130\right.$ cells $/ \mathrm{cm}^{2}$; range, 70-240) was significantly higher than in the BT negative subjects $\left(100 \mathrm{cells} / \mathrm{cm}^{2}\right.$; range, 70-140; $\mathrm{p}<0.05$, Mann-Whitney U test). The median frequency of IgM positive cells was also higher in the BT positive patients than in the BT negative patients (40 cells $/ \mathrm{cm}^{2}$; range, 20-90 $v 30 / \mathrm{cm}^{2}$; range $\left.10-50\right)$, although this difference was not significant $(p>0.05$, MannWhitney U test) (fig 1).

Table 2 shows the results obtained from the analysis of $\operatorname{IgA}$ and $\operatorname{IgM}$ values at the mucosal surface. Some degree of staining was present in 


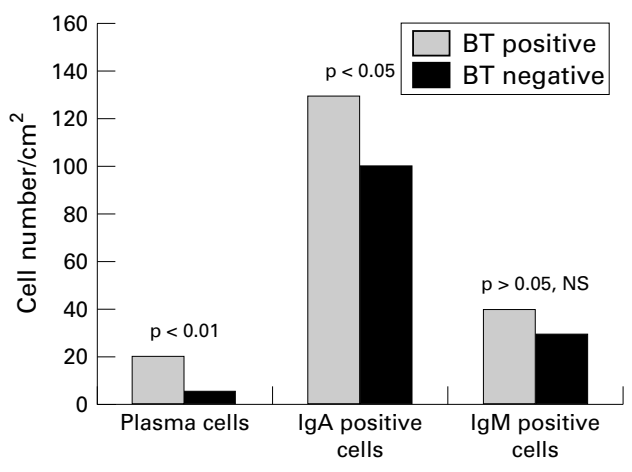

Figure 1 Median number of plasma cells, IgA positive cells, and IgM positive cells in BT positive and negative patients.

Table 2 Semiquantitatively scored IgA and IgM concentrations at the mucosal surface

\begin{tabular}{lll}
\hline & $\begin{array}{l}\text { BT positive } \\
\text { group }\end{array}$ & $\begin{array}{l}\text { BT negative } \\
\text { group }\end{array}$ \\
\hline IgA High & 2 & 0 \\
3 Hoderate & 9 & 5 \\
1 Low & 0 & 6 \\
IgM & & \\
3 High & 1 & 0 \\
2 Moderate & 8 & 3 \\
1 Low & 2 & 8 \\
\hline
\end{tabular}

BT, bacterial translocation

each of the patients studied. All 11 patients in the BT positive group were deemed to have an IgA score of 2 or 3 (moderate or high degree of staining, respectively), compared with only five of the BT negative patients ( $p=0.006$, Fisher's exact test mid p). Similarly, an IgM score of 2 or 3 was found in nine BT positive patients, compared with only three patients in the BT negative group ( $p=0.016$, Fisher's exact test mid p).

\section{Discussion}

Our results suggest that BT, confirmed by positive culture from a mesenteric lymph node, is associated with a significant increase in gut immune function.

In a large prospective study, BT was demonstrated in $15.4 \%$ of patients undergoing laparotomy, and was associated with a significant increase in the incidence of postoperative septic morbidity. ${ }^{2}$ One mechanism proposed as a promoter of this phenomenon is a deficiency in local gut immune defences. In the normal intestinal mucosa, substantial numbers of plasma cells are present in the lamina propria, producing $\operatorname{IgA}$ and smaller amounts of $\operatorname{IgM}$. In its dimeric form, $\operatorname{IgA}$ is actively bound to the protein secretory component (SC) while traversing the overlying epithelial layer by endocytosis. SC is produced by the epithelial cells, and facilitates the transport of IgA into secretions and protects it from proteolytic attack. SC is removed by proteolytic cleavage to release free IgA into the mucus layer on the luminal surface of the enterocyte. ${ }^{16}{ }^{17} \mathrm{IgM}$ is secreted in its pentameric form and reaches the mucosal surface in a similar manner.

These immunoglobulins at the mucosal surface provide an important part of the normal barrier mechanism of the intestinal mucosa, binding to bacterial antigens and limiting adherence of pathogens to the wall of the enterocyte, the initial step in the process of $\mathrm{BT} .^{10}$ Alverdy et al showed that a significant decrease in $\operatorname{IgA}$ was associated with an increase in bacterial translocation in rats given total parenteral nutrition. ${ }^{18}$ The beneficial effects of IgA in limiting translocation have also been demonstrated previously in both animal and in vitro studies. A study by Albanese et al, using an in vivo model in rats, showed that $E$ coli was unable to cross a morphologically intact segment of small bowel tissue while bound to IgA, a phenomenon they termed immune exclusion. ${ }^{19}$ Von Specht et al found that IgA directed against a $P$ aeruginosa outer membrane protein was protective against translocation of this organism in immunosuppressed mice. ${ }^{20}$. An in vitro study by Diebel et al demonstrated that the addition of IgA significantly reduced BT across epithelial cell monolayers following an inoculum of bacteria. ${ }^{21}$

Coutinho et al took small bowel specimens from 17 patients with intra-abdominal sepsis and stained them immunohistochemically for several markers of immune function, including IgA and IgM. ${ }^{9}$ These were compared with control specimens obtained from two transplant donors. They found the numbers of IgA and IgM positive plasma cells to be reduced in the patients with sepsis, although no numerical data were presented in the paper. These findings were explained on the basis of an increase in glucocorticoid secretion as part of the stress response to sepsis causing apoptosis of mucosal plasma cells and a reduction in immunoglobulin production. It was proposed that this predisposes to adhesion of luminal bacteria to the apical surface of the enterocyte and consequent translocation across the epithelium. However, the occurrence of BT in these patients was only presumed; no direct confirmatory evidence was provided.

Our study is the only in vivo study of BT in relation to gut immune function in humans. Our results are at variance with the inferences made from the Coutinho study because we found a significant increase, rather than a decrease, in the gut immune response in those patients in whom BT had been positively identified. We did not stain for SC or J chain because these variables appeared to correspond closely to the immunoglobulin values in the Coutinho study, so we felt that they would not provide any useful additional information. Morphological assessment of apoptosis can be misleading, and in situ hybridisation techniques can be unreliable, particularly on formalin fixed specimens. ${ }^{22}$ Furthermore, in situ hybridisation is beyond the technical scope of our laboratory at present. We feel that using numbers of human major histocompatibility complex (HLA) DR positive macrophages in the lamina propria as a measure of apoptosis, as in the Coutinho study, is too simplistic and unreliable. For these reasons we did not attempt to assess plasma cell apoptosis.

A possible explanation for the discrepancy between the results of the two studies could relate to variability of specimen fixation time, 
fixative type, temperature of fixation, and differences in processing schedules in the Coutinho study. Such variability is inevitable when specimens are drawn from more than one centre on a retrospective basis. This variability can adversely influence immunohistochemical staining significantly. A further possible explanation is the difference in disease severity between the patients in the two studies - most of our patients were undergoing elective procedures and were thus not septic at the time of surgery. Our results suggest that, at least in these predominantly elective surgical patients, the increased immunoglobulin values seen in those patients with a positive MLN is a secondary phenomenon, occurring in response to the translocation of bacteria across the mucosa. In vitro studies have demonstrated that invasion of colonic epithelial cells by enteric bacteria results in enhanced cytokine expression, which acts as a signal to immunoreactive cells such as B cells in the lamina propria. ${ }^{23}$ We cannot confirm the proposed hypothesis that suppression of the immune response, such as that induced by sepsis, predisposes to BT. Furthermore, there is no evidence from our results that BT itself impairs the systemic and intestinal immune response as suggested by previous animal studies. ${ }^{24} 25$

Almost all of the small bowel specimens were from the terminal ileum, removed as part of a right hemicolectomy or total colectomy. This negates the effect of any variation in the local immune response along the length of the small bowel. By analysing only normal segments of intestine we have attempted to remove confounding influences related to the primary disease process, as well as providing a more representative measure of overall gut immune function. It is not known whether the immune response was similar in the diseased intestine, but we consider this to be of little importance because the pathology was very localised in most of our patients. Furthermore, we have previously demonstrated the occurrence of BT in patients with "normal" intestine, such as those undergoing abdominal aortic aneurysm repair. ${ }^{26}$ Upregulation of the immune response has been described in patients with inflammatory bowel disease (IBD). ${ }^{27}$ We found no significant differences in any of the parameters of immune function in the six patients with IBD compared with the other patients in our study.

It is interesting to note that the frequency of IgA positive cells was greater than that of plasma cells in every case studied, and the frequency of $\operatorname{IgM}$ positive cells was greater in all but five cases. We accept the fact that using morphology alone to identify plasma cells may underestimate their true frequency. In addition, some of the cells that stained positively for $\operatorname{IgA}$ and $\operatorname{IgM}$ might be macrophages rather than plasma cells. However, these considerations do not alter the fact that significant differences were seen between the two patient groups in terms of four of the five parameters measured, including $\operatorname{IgA}$ and $\operatorname{IgM}$ values at the mucosal surface.
Our findings infer that factors other than intestinal mucosal immunity must be important in the promotion of BT. The most likely of these is bacterial overgrowth within the gut lumen. IgA synthesis by B cells of the gut associated lymphoid tissue increases in response to the overgrowth of bacteria. ${ }^{28}$ Colonisation of the proximal gastrointestinal tract is common in critically ill patients, largely as a result of increased gastric $\mathrm{pH}$ and reduced peristalsis, and is associated with increased rates of septic complications. $^{729}$ A recently published paper from our unit describes the association between gastric colonisation, bacterial translocation, and septic morbidity. ${ }^{6}$ These findings provide a rationale for the use of selective gut decontamination in those patients at risk of gut derived sepsis, and a recent meta-analysis confirmed a reduction in both nosocomial pneumonia and mortality associated with this technique in patients treated in intensive care units. ${ }^{30}$

In conclusion, we have found a significant increase in immune function in the small bowel mucosa of patients in whom bacterial translocation has been shown to occur. We hypothesise that this represents a response to the occurrence of BT, and challenges previous claims that BT occurs secondary to a reduction in local immune responsiveness. Therapeutic interventions that prevent pathological bacterial overgrowth within the gastrointestinal tract may be the most appropriate means of decreasing BT and thus potentially reducing the incidence of gut derived sepsis.

1 Sedman PC, MacFie J, Sagar P, et al. The prevalence of gut translocation in humans. Gastroenterology 1994;107:643-9.

2 O'Boyle CJ, MacFie J, Mitchell CJ, et al. Microbiology of bacterial translocation in humans. Gut 1998;42:29-35.

3 Deitch EA. Multiple organ failure. Ann Surg 1992;216:11734.

4 Lemaire LCJM, van Lanschot JJB, Stoutenbeek CP, et al. Bacterial translocation in multiple organ failure: cause or epiphenomenon still unproven. Br f Surg 1997;84:134050 .

5 Deitch EA. Nutrition and the gut mucosal barrier. In: Daly $\mathrm{J}$, ed. Current opinion in general surgery. Philadelphia: Current Science, 1993:85-91.

6 MacFie J, O'Boyle CJ, Mitchell CJ, et al. Gut origin of sepsis: a prospective study investigating associations between bacterial translocation, gastric microflora and septic morbidity. Gut 1999;45:223-8.

7 Marshall JC, Christou NV, Meakins JL. The gastrointestinal tract. The "undrained abscess" of multiple organ failure. Ann Surg 1993;218:111-19.

8 O'Boyle CJ, MacFie J, Dave K, et al. Alterations in intestinal barrier function do not predispose to translocation of enteric bacteria in gastroenterologic patients. Nutrition 1998;14:358-62.

9 Coutinho HB, Robalinho TI, Coutinho VB, et al. Intraabdominal sepsis: an immunocytochemical study of the
small intestine mucosa. $\mathcal{F}$ Clin Pathol 1997;50:294-8.

10 Katayama $\mathrm{M}$, Xu D, Specian RD, et al. Role of bacterial adherence and the mucus barrier in bacterial translocation. Ann Surg 1997;225:317-26.

11 Berg RD. Translocation of indigenous bacteria from the intestinal tract. In: Hentges DJ, ed. Human intestinal microflora in health and disease. San Diego: Academic Press, 1983:332-52

12 Williams JH, Mepham BL, Wright DH. Tissue preparation for immunohistochemistry. F Clin Pathol 1997;50:422-8.

13 van Diest PJ, van Dam P, Henzen-Logmans SC, et al. A scoring system for immunohistochemical staining: consensus report of the task force for basic research of the EORTC-GCCG. F Clin Pathol 1997;50:801-4.

14 Adams EJ, Green JA, Clark AH, et al. Comparison of different scoring systems for immunohistochemical staining. $\mathcal{F}$ Clin Pathol 1999;52:75-7.

15 Armitage P, Berry G. Exact probability test. In: Armitage P, ed. Statistical methods in medical research. Oxford: Blackwell Scientific Publications, 1994:123-4.

16 McVay LD. Immunology of the gut. In: Rombeau JL, Takala J, eds. Gut dysfunction in critical illness. Berlin: Springer-

17 Mestecky J, Lue C, Russell MW. Selective transport of IgA. Cellular and molecular aspects. Gastroenterol Clin North Am 1991;20:441-71. 
18 Alverdy JC, Aoys E, Moss GS. Total parenteral nutrition promotes bacterial translocation from the gut. Surgery 185-90.

19 Albanese CT, Smith SD, Watkins S, et al. Effect of secretory IgA on transepithelial passage of bacteria across the intact ileum in vitro. $7 \mathrm{Am}$ Coll Surg 1994;179:679-88.

20 von Specht B, Knapp B, Hungerer K, et al. Outer membrane proteins of Pseudomonas aeruginosa as vaccine candidates. F Biotechnol 1996;44:145-53.

21 Diebel LN, Liberati DM, Dulchavsky SA, et al. An in vitro model to assess mucosal immune function and bacterial translocation. 7 Surg Res 1997;69:178-82.

$22 \mathrm{McNicol}$ AM, Farquharson MA. In situ hybridisation and its diagnostic applications in pathology. F Pathol 1997;182 $250-261$

23 Eckmann L, Kagnoff MF, Fierer J. Epithelial cells secrete the chemokine interleukin-8 in response to bacterial entry. Infect Immun 1993;61:4569-74.

24 Deitch EA, Xu D, Lu O, et al. Bacterial translocation from the gut impairs systemic immunity. Surgery 1991;109:269the gut impairs systemic immunity. Surgery 1991;109:269-
25 Xu D, Lu O, Deitch EA. Elemental diet-induced bacterial translocation associated with systemic and intestinal immune suppression. FPEN f Parenter Enteral Nutr 1998;22:37-41.

26 Woodcock NP, Sudheer V, El-Barghouti N, et al. Bacterial translocation in patients undergoing abdominal aortic aneurysm repair. Br F Surg 2000;87:439-42.

27 Strober W, Kelsall B, Marth T. Oral tolerance. f Clin Immunol 1998;18:1-30.

28 Lichtman S, Sherman P, Forstner G. Production of secretory immunoglobulin A in rat self-filling blind loops. Local secretory immunoglobulin A immune response to luminal bacterial flora. Gastroenterology 1986;91:1495-502.

29 Marshall JC. Gastrointestinal flora and its alterations in critical illness. Curr Opin Clin Nutr Metab Care 1999;2: 405-11.

30 D'Amico R, Pifferi S, Leonetti C, et al. Effectiveness of antibiotic prophylaxis in critically ill adult patients: systematic review of randomised controlled trials. BMF 1998;316: $1275-85$.

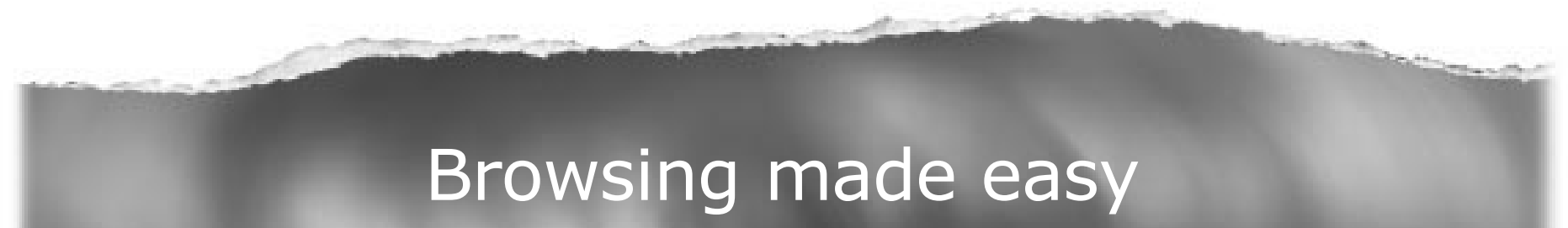

\section{Collections}

With a single click Collections allows you to find all articles that have been published in your chosen subject. Select from over 200 clinical and non-clinical topic collections and/or cross search other specialist journals, the BMJ and Cochrane Reviews

www.jclinpath.com 